\title{
SUSTENTABILIDADE E ESTRATÉGIAS DE REPRODUÇÃO SOCIAL DA AGRICULTURA FAMILIAR NA AMAZONIA ORIENTAL
}

\author{
Simone Alves Martins ${ }^{1}$; Myriam Cyntia Cesar de Oliveira ${ }^{2}$. \\ ${ }^{1}$ Discente do Curso de Ciências Sociais da Universidade Federal do Pará, Bolsista PIBIC-PARD, \\ simonealves_m@hotmail.com \\ ${ }^{2}$ Professora Dra. do Núcleo de Ciências Agrárias e Desenvolvimento Rural da Universidade Federal do Pará, \\ myriam@ufpa.br
}

\begin{abstract}
RESUMO: Na busca de garantir a reprodução social de sua família dentro das atuais condições do contexto regional, os agricultores da fronteira de Marabá têm procurado adotar novas estratégias produtivas e sociais. Os estabelecimentos familiares estão passando por processos de adaptação dos sistemas de produção no sentido de aumentar as possibilidades de permanência no lugar. $\mathrm{O}$ presente trabalho tem por objetivo apresentar algumas das novas estratégias de reprodução social utilizadas por agricultores familiares em assentamentos na região de Marabá. A pesquisa foi realizada nos assentamentos Lago Azul e Palmeira Jussara, a partir de uma amostra de 33 estabelecimentos familiares, tendo sido utilizados roteiros semiestruturados e questionários para o levantamento empírico. Foram observadas alterações de estratégias que se direcionam para a diversificação das atividades produtivas e para a diversificação das fontes de renda que podem colaborar para a reprodução social dos agricultores e para a sustentabilidade de seus sistemas.
\end{abstract}

PALAVRAS-CHAVE: adaptação, manutenção, sistemas de produção.

\section{SUSTAINABILITY STRATEGIES AND SOCIAL REPRODUCTION OF FAMILY FARMING IN EASTERN AMAZON}

\begin{abstract}
In seeking to ensure the social reproduction of their families within the regional context of current conditions, farmers in Maraba frontier have sought to adopt new production and social strategies. The family farms are going through processes of adaptation of production systems to increase the possibilities of remaining in place. This paper aims to present some of the new social reproduction strategies used by family farmers in settlements in the region of Maraba. The survey was conducted in the settlements Blue Lake and Palm Jussara, from a sample of 33 family farms, having been used semi-structured and structured questionnaires for the empirical study. Changes were observed from strategies that target the diversification of productive activities and the diversification of income sources that can contribute to social reproduction of farmers and sustainability of their systems.
\end{abstract}

KEY-WORDS: adaptation, maintenance, production systems.

$\begin{array}{ccccc}\text { Este trabalho tem por objetivo } & \text { Jussara, na região de Marabá. Segundo } \\ \text { apresentar algumas das estratégias de } & \text { Deponti e Almeida (2002), para a } \\ \text { reprodução social } & \text { observadas nos } & \text { reprodução social e manutenção dos } \\ \text { assentamentos Lago Azul e Palmeira } & \text { sistemas de produção se faz necessária a }\end{array}$


interação das dimensões ambiental, econômica, social e cultural que compõem a ideia de sustentabilidade, sendo que quanto maior o grau de interação e equilíbrio entre elas maior possibilidade de sustentação do sistema.

A durabilidade de um sistema produtivo é construída a partir de um movimento dinâmico, que além da interação entre as dimensões da sustentabilidade, há o processo de adaptação, entendido como contínuas transformações e reconstruções dos modos de vidas que são expressas pelas diferentes estratégias efetuadas mediante as condições disponíveis (GODELIER, 1984 apud OLIVEIRA, 2009).

Nos assentamentos pesquisados, as atuais estratégias têm influenciado nas práticas adotadas e no funcionamento dos sistemas de produção na medida em que estão sendo alteradas no sentido de garantir a reprodução social das famílias.

Nesta pesquisa de caráter qualitativo foi utilizada uma amostra de 33 estabelecimentos familiares, sendo 18 entrevistas realizadas no Lago Azul e 15 no Palmeira Jussara, escolhidos em função da sua facilidade de acesso, proximidade da cidade e de indicações de mudanças nas práticas produtivas dos agricultores. Para o levantamento de campo foram utilizados roteiros semi-estruturados e questionários.
O assentamento Lago Azul localizado no município de Nova Ipixuna, a $38 \mathrm{~km}$ de Marabá, teve suas primeiras ocupações entre os anos de 1985 e 1986, com regularização em 2000. O Lago Azul possui 96 famílias assentadas. Já o Palmeira Jussara é um assentamento com ocupações dos anos de 1998 e regularização em 2003, situado no município de Marabá a $21 \mathrm{~km}$ da sede do município, abrigando 67 famílias.

Embora na sua ocupação fosse área coberta de mata, o Lago Azul, por ser mais antigo, passou por um período de exploração mais longo, o que explica seu baixo percentual de mata atualmente (inferior a 20\%) ${ }^{1}$ e as condições desfavoráveis de solo, com a baixa de fertilidade. Como utilizam ainda o sistema de corte-queima para preparo da área para cultivos, essa escassez de mata constitui-se em uma restrição para os sistemas de produção praticados no assentamento. Já no Palmeira Jussara, ao contrário do Lago Azul onde as reservas de mata eram abundantes no início da ocupação, a grande maioria das famílias teve que começar o processo de exploração do lote dispondo de pouca (senão nenhuma) reserva de mata/capoeira visto que o assentamento foi criado em área de uma antiga fazenda e já

\footnotetext{
${ }^{1}$ Os estabelecimentos pesquisados possuíam, em média, somente $17 \%$ de sua área total coberta por mata/capoeira.
} 
havia sofrido exploração madeireira. Atualmente, os percentuais de vegetação primária e secundária não são superiores a $25 \%{ }^{2}$.

As novas estratégias de reprodução social observadas nos assentamentos pesquisados podem ser reunidas em três grandes grupos: novas atividades agropecuárias; novas práticas produtivas e sociais; e atividades não-agricolas. Estas fazem parte do processo de adaptação presente na busca por manutenção dos sistemas produtivos, já que estão reinventando os seus modos de vida e se adaptando às condições disponíveis.

As estratégias relacionadas às novas atividades produtivas na unidade agrícola dizem respeito à inserção de atividades como: piscicultura, produção de mel, cultivos de hortas, melancia, cultivos de espécies perenes e semi-perenes. A entrada destas atividades nas unidades familiares visa à diversificação do sistema de produção.

Para algumas destas atividades observou-se que há necessidade de mudanças nas formas de manejo e nas relações sociais estabelecidas, levando os agricultores a experimentarem novas práticas produtivas e sociais. Entre essas práticas sociais destaca-se a formação de

\footnotetext{
${ }^{2}$ Os estabelecimentos pesquisados possuíam, em média, somente $23 \%$ de sua área total coberta por mata/capoeira
}

grupos para a realização dos cultivos das hortas em mutirões. Nas práticas produtivas pode-se citar: as formas de preparar a terra, como plantar e em que espaço plantar.

Um exemplo dessas novas práticas produtivas é a utilização de preparo mecanizado de alguns dos cultivos de melancia e hortas, sendo que esses cultivos podem ser feitos em áreas de terras firmes dentro do próprio assentamento ou fora dele em áreas de vazantes. Observou-se a utilização de adubação nos cultivos, seja a partir de insumos químicos (adubos) ou adubos orgânicos como ocorre com as hortas no sistema de Mandalla ${ }^{3}$. Além disso, foram verificadas experiências de cultivos realizados em associações e até mesmo em coletivos, como é o caso das hortas. Estas práticas de produção podem ser entendidas como uma estratégia de melhor gestão do espaço e as práticas sociais de associação ou coletivo visa à diminuição dos riscos e vulnerabilidade da produção bem como a facilidade de escoamento, uma vez que os agricultores dispõem de maior mão-de-obra com as formações de grupos.

Também foram observadas novas práticas produtivas na condução de

\footnotetext{
3 “O projeto, batizado de Mandalla (círculos em sânscrito) utiliza tecnologia simples e de baixo custo. São construídos [...] canteiros ao redor de um lago circular [...]. A água do lago é bombeada para irrigar a plantação" (MARIUZZO, 2007).
} 
atividades tradicionalmente desenvolvidas nos sistemas de produção dos agricultores, como nos cultivos anuais. As roças eram preparadas através do corte-queima com retirada da mata ou capoeirão de maneira a evitar o mesmo espaço para plantar novamente. Observou-se não apenas o uso do corte-queima para preparo das roças, mas a adoção da mecanização. E algumas das famílias que utilizam da técnica do corte-queima estão fazendo de maneira a rotacionar o local de plantio dos cultivos. O "sistema rotacionado" de roças consiste em destinar uma parte do lote para fazer os cultivos anuais de forma a descansar uma parte dessa área, realizando o pousio.

O solo apresenta baixa fertilidade segundo os agricultores, o que leva a tentativas de alterar o manejo das roças se apoiando na estratégia do autoconsumo, que mesmo com o meio natural adverso insistem nos cultivos anuais, pois são importantes para a reprodução social, principalmente na material, pela garantia de alimentos (GAZOLLA; SCHNEIDER, 2007).

Entre as novas estratégias estão ainda aquelas que se referem às atividades de beneficiamento de produtos ou mesmo desenvolvidas fora da agricultura, como forma de aumentar o nível de diversificação das fontes de renda do estabelecimento. Além das atividades agrícolas inseridas recentemente, há outras que podem ser classificadas como não agrícolas, como a oferta de serviços e de beneficiamento de produtos. Ambos os assentamentos têm relações com os centros urbanos, sobretudo o Palmeira Jussara, mais próximo da sede de Marabá. Isso facilita a entrada de influências de agentes externos, abrindo possibilidades para que combinassem atividades agrícolas com não agrícolas. Ou seja, abre possibilidade para que os agricultores da região lancem mão da estratégia da pluriatividade ${ }^{4}$.

Há oferta de serviço como professor, pedreiro, cabeleireiro e comerciante; tendo produção de redes de tecidos, cultivos de flores ornamentais e beneficiamentos de queijos e doces. Estas atividades complementam a renda das famílias.

Todas estas estratégias observadas fazem parte do processo de adaptação que os agricultores familiares sofrem para se reproduzirem e manterem o seu sistema social, como já foi afirmado. A sustentabilidade do sistema se faz através de adaptação e recriação dos modos de vida. Estas estratégias podem colaborar para a manutenção das famílias e dos sistemas por estar promovendo a diversificação das atividades e aumentando as opções de rendas.

4 A pluriatividade consiste na combinação de atividades agrícolas (cultivos anuais e perenes, pecuária mista, etc) com as não-agricolas (oferta de serviços de beneficiamento, etc) sendo que esta soma direciona-se para a reprodução social. 
Segundo Hurtienne (2005) a possível estabilização dos sistemas de produção ocorre por meio da complexificação da unidade produtiva, ou seja, da diversificação das atividades. Desta maneira, a diversificação nos assentamentos estudados pode contribuir para a sustentabilidade do sistema uma vez que envolve uma possível estabilização. Além disso, segundo Schneider (2001), a pluriatividade é um mecanismo importante na manutenção dos sistemas e dos agricultores familiares já que diminuem os riscos do mercado, caso que dificilmente acontece quando se trata de atividades agrícolas.

Neste trabalho pretendeu-se demonstrar que algumas das estratégias de reprodução social da agricultura familiar estudadas na região de Marabá podem estar proporcionando a sustentabilidade dos assentados nos lotes através de maiores possibilidade de manutenção das unidades produtivas por meio da diversificação das atividades produtivas e diversidade das fontes de renda.

A inserção destas diversificações muitas vezes é apoiada em recursos como o Bolsa Família, pensão ou aposentadoria. Estas diversificações - embora se tenha iniciativas de atividades ou práticas de menor dependência dos elementos externos, como as hortas onde ocorre a utilização de adubos orgânicos - podem constituir-se em estratégias que envolvem o uso de adubos químicos e mecanização. As estratégias em geral visam à manutenção do sistema, porém algumas são pensadas e sustentáveis apenas a curto prazo, pois a médio/longo prazo podem gerar outros problemas produtivos.

\section{REFERÊNCIAS}

DEPONTI, C.; ALMEIDA J. Indicadores para avaliação da sustentabilidade em contextos de desenvolvimentos rural local. 2002. Disponível em: $<$ http://biblioteca.planejamento.gov.br/bibl ioteca-tematica-1/textos/desenvolvimentoagrario/texto-31-indicadores-paraavaliacao-da-sustentabilidade-emcontextos-de-desenvolvimento-rurallocal.pdf >. Acesso em: 07 jun. 2011.

GAZOLLA, Márcio; SCHNEIDER, Sergio. A produção da autonomia: os "papeis" do autoconsumo na reprodução social dos agricultores familiares. Revista Estudos Sociedade e Agricultura. v.15, p.89-122. Rio de Janeiro: 2007. Disponível em: < http://r1.ufrrj.br/esa/art/200704-089122.pdf > Acesso em: 18 jan. 2011.

HURTIENNE, Thomas. Agricultura familiar e desenvolvimento rural sustentável na Amazônia. Novos Cadernos NAEA. vol. 8. $\mathrm{n}^{\circ}$ 01. p. 54-59. 2005. Disponível em: < http://www.periodicos.ufpa.br/index.php/n 
cn/article/view/47/42 >. Acesso em: 11 jan. 2011.

MARIUZZO, Patrícia. Sistema baseado em agricultura sustentável ajuda pequenos produtores. Inovação Uniemp. Vol. 3, nº 2 . Campinas: 2007. Disponível em: < http://inovacao.scielo.br/scielo.php?script= sci_arttext\&pid=S180823942007000200026\&lng=es\&nrm=iso >. Acesso em: 11 jan. 2011

OLIVEIRA, Myriam Cyntia C. Agricultura familiar e dinâmicas das relações sociedade-natureza em área de fronteira agrária na Amazônia oriental. 2009. Tese (Doutorado). Programa de Pós-Graduação em Desenvolvimento Rural, Universidade Federal do Rio Grande do Sul, Porto Alegre: 2009.

SCHNEIDER, Sergio. A pluriatividade como estratégia de reprodução social da agricultura familiar no Sul do Brasil. Estudos Sociedade e Agricultura. Rio de Janeiro, v. 16, p. 164-184, 2001. 